\title{
Parasitoidism, not sociality, is associated with the evolution of elaborate mushroom bodies in the brains of hymenopteran insects
}

\author{
Sarah M. Farris ${ }^{1, *}$ and Susanne Schulmeister ${ }^{2}$ \\ ${ }^{1}$ Department of Biology, West Virginia University, Morgantown, WV 26505, USA \\ ${ }^{2}$ Division of Invertebrate Biology, American Museum of Natural History, New York, NY 10024, USA
}

\begin{abstract}
The social brain hypothesis posits that the cognitive demands of social behaviour have driven evolutionary expansions in brain size in some vertebrate lineages. In insects, higher brain centres called mushroom bodies are enlarged and morphologically elaborate (having doubled, invaginated and subcompartmentalized calyces that receive visual input) in social species such as the ants, bees and wasps of the aculeate Hymenoptera, suggesting that the social brain hypothesis may also apply to invertebrate animals. In a quantitative and qualitative survey of mushroom body morphology across the Hymenoptera, we demonstrate that large, elaborate mushroom bodies arose concurrent with the acquisition of a parasitoid mode of life at the base of the Euhymenopteran (Orussioidea + Apocrita) lineage, approximately $90 \mathrm{Myr}$ before the evolution of sociality in the Aculeata. Thus, sociality could not have driven mushroom body elaboration in the Hymenoptera. Rather, we propose that the cognitive demands of host-finding behaviour in parasitoids, particularly the capacity for associative and spatial learning, drove the acquisition of this evolutionarily novel mushroom body architecture. These neurobehavioural modifications may have served as pre-adaptations for central place foraging, a spatial learning-intensive behaviour that is widespread across the Aculeata and may have contributed to the multiple acquisitions of sociality in this taxon.
\end{abstract}

Keywords: brain evolution; learning and memory; parasitoid

\section{INTRODUCTION}

The insect mushroom bodies are brain centres that participate in an array of higher order functions including olfactory associative learning and olfactory processing [1-3], spatial learning $[4,5]$, sensory integration, sensory filtering and attention [6-12]. The mushroom bodies have a characteristic morphology consisting of a pedunculus and lobes composed of the parallel fibre-like projections of thousands of intrinsic neurons called Kenyon cells, and calyces composed of Kenyon cell dendrites that receive afferent input from primary sensory neuropils [13-16].

The first study of insect mushroom bodies by Dujardin [17] made note of their large size and morphological complexity in the social species of the aculeate Hymenoptera. Since then, a relationship between large, morphologically complex mushroom bodies and sociality in insects has been tacitly accepted, although never explicitly tested [18-20]. The social brain hypothesis, as proposed for some vertebrate taxa, posits that the cognitive demands of social behaviour have driven evolutionary expansions in overall brain size and in brain regions such as the telencephalon ([21-27]; but

* Author for correspondence (sarah.farris@mail.wvu.edu).

Electronic supplementary material is available at http:/dx.doi.org/ 10.1098/rspb.2010.2161 or via http://rspb.royalsocietypublishing.org.

One contribution to a Special Feature 'Information processing in miniature brains'. see $[28,29]$ for instances in which sociality does not clearly correlate with increased brain size). As applied to the Hymenoptera, the hypothesis would predict that large, morphologically complex mushroom bodies should be found only in those lineages containing social species, and not in the more basal lineages consisting only of solitary species.

The mushroom bodies of the social aculeate Hymenoptera are typified by those of the honeybee, Apis mellifera (figure 1) [30-32]. In particular, the calyces are doubled, deeply cup-shaped and greatly expanded in size in relation to the lobes [33], a morphology we refer to here as 'elaborate'. The calyces of social aculeates also receive visual input from the medulla and lobula of the optic lobes, in addition to olfactory and gustatory inputs that are more generally observed across the insects [31,34-37]. Morphologically distinct subcompartments in the calyces receive input from each of these sensory modalities, with the collar region specifically receiving optic lobe input [31].

The Hymenoptera comprise one of the largest and most diverse insect orders. The ancestral species from which all Hymenoptera evolved probably had phytophagous larvae, as do extant members of the basal lineages [38] (figure 2). A prominent step in hymenopteran evolution was the transition from phytophagy to parasitism at the base of the Euhymenoptera, a group that contains the superfamily Orussoidea and the Apocrita $[38,39]$. Monophyly of Euhymenoptera is strongly supported by morphological, molecular and joint analyses [40-42]. 

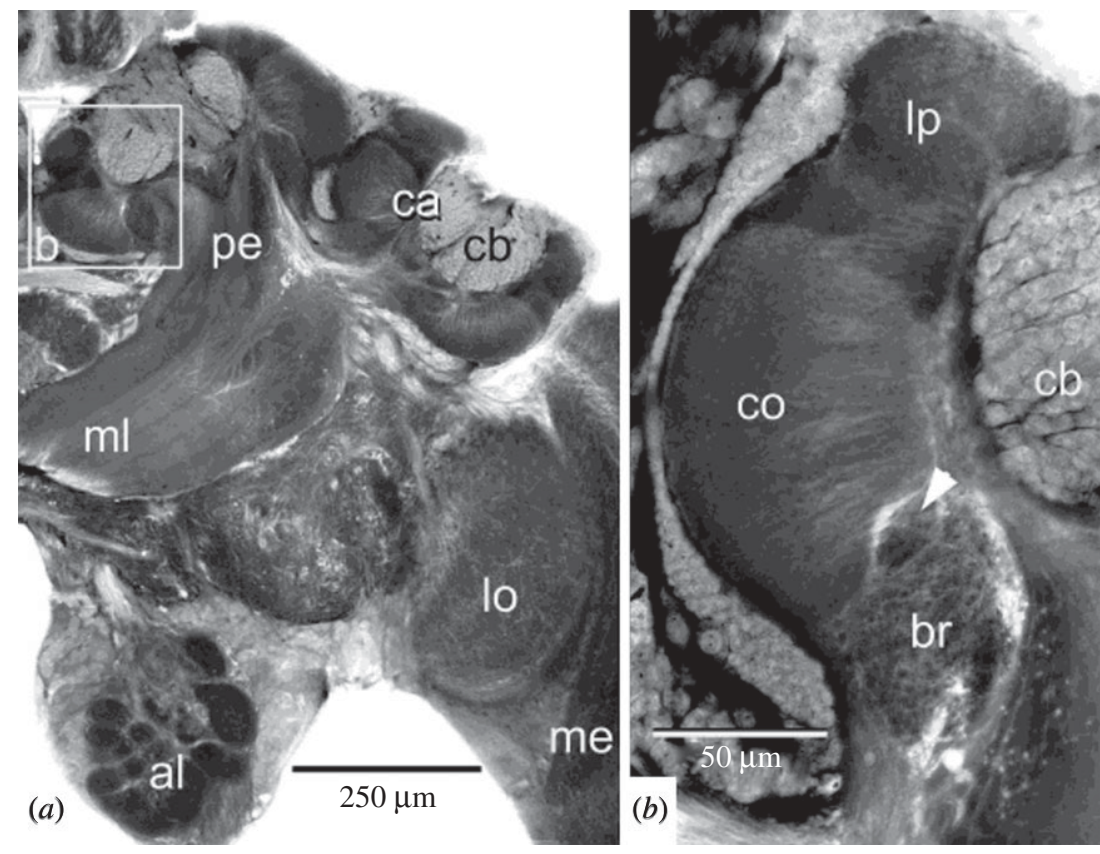

Figure 1. Mushroom body architecture in aculeate hymenopterans, as illustrated by the honeybee Apis mellifera (Apidae, Apoidea). (a) The mushroom body neuropil consisting of the calyces (ca), pedunculus (pe) and lobes (medial lobe (ml) visible in this plane of section). The calyces are elaborated into deeply invaginated cups, and the cell bodies of mushroom body intrinsic neurons, called Kenyon cells (cb) fill and surround the calyces. (b) High-magnification view of boxed area in (a) showing functional subdivisions of the calyx. Olfactory projection neurons target the lip (lp), visual projection neurons target the collar (co) and the basal ring (br) receives collaterals from both. Figures borrowed with permission from Ehmer \& Gronenberg [37].

Thus, the present account will not use the traditional classification of Hymenoptera as divided into Symphyta and Apocrita, but will instead refer to 'phytophagous lineages' versus Euhymenoptera.

Another prominent step in the evolution of the Hymenoptera was the transformation of the ovipositor into a stinger in the ancestor of Aculeata in the late Jurassic and early Cretaceous [43]. The Aculeata are split into Chrysidoidea and a clade comprising Vespoidea and Apoidea. Eusociality was another important evolutionary innovation and has probably evolved four times independently within Vespoidea and Apoidea [44].

In the first test of the evolutionary relationship between sociality and brain morphology in an invertebrate clade, we examined mushroom body morphologies of solitary species representing nearly all major hymenopteran lineages outside of the Aculeata, one basal solitary aculeate and one social aculeate (electronic supplementary material, table $\mathrm{S} 1$ ). We sought to identify three events in the evolution of hymenopteran mushroom bodies, and to determine whether any of these events was associated with the acquisition of sociality: (i) the expansion of mushroom body volume relative to the rest of the brain, (ii) the expansion of the calyces relative to the lobes, and (iii) the acquisition of visual inputs to the calyces from the optic lobes. Volumes of the mushroom bodies, their calyces and lobes were obtained from measurements of histological preparations, and when available, live-captured insects were used for fluorescent dextran tracing of optic lobe inputs to the mushroom bodies. These data were also compared with accounts of mushroom body morphologies of social and solitary aculeates from the published literature (electronic supplementary material, table $\mathrm{S} 1$ ).

\section{MATERIAL AND METHODS}

\section{(a) Insects}

Insects were either live-captured in the Morgantown, WV area or obtained as ethanol- or alcoholic Bouin's-preserved specimens.

\section{(b) Analysis of mushroom body morphology}

Live-captured specimens were chilled on ice and brains dissected in physiological saline [45]. Brains were processed in one of two ways: (i) fixed in Carnoy's fixative for $2 \mathrm{~h}$ at room temperature and stored in 70 per cent ethanol at $4^{\circ} \mathrm{C}$ overnight, embedded in paraffin, sectioned at $10 \mu \mathrm{m}$ on a rotary microtome and processed for Cason's staining [46]; or (ii) fixed in 4 per cent paraformaldehyde in phosphatebuffered saline overnight at $4{ }^{\circ} \mathrm{C}$, embedded in agarose, vibratome sectioned at $70 \mu \mathrm{m}$, and immunostained using the anti-DC0 antibody as described by Farris [47]. The anti-DC0 antibody (a gift of Dr Daniel Kalderon) robustly stains insect Kenyon cells [16,48]. For Cason's stained brains, mushroom body and protocerebral volumes were calculated from area measurements of traced brain regions from $10 \mu \mathrm{m}$ paraffin sections using Zeiss AxioVision 4 software (Carl Zeiss AG, Oberkochen, Germany) as described by Farris \& Roberts [49]. For anti-DC0 stained brains, sections were viewed on an Olympus Fluoview 1000 confocal microscope, and image stacks consisting of $10 \mu \mathrm{m}$ optical sections of each section captured and saved as avi files. Files were imported into IMAGEJ 1.43u software (http://rsbweb.nih. gov/ij/) for quantification of brain volumes using a pointcounting grid ('Grid' plug-in). Points falling within each brain region of interest were counted for each optical section, and volumes were calculated from point numbers taking into account magnification, section thickness and grid size [50]. 


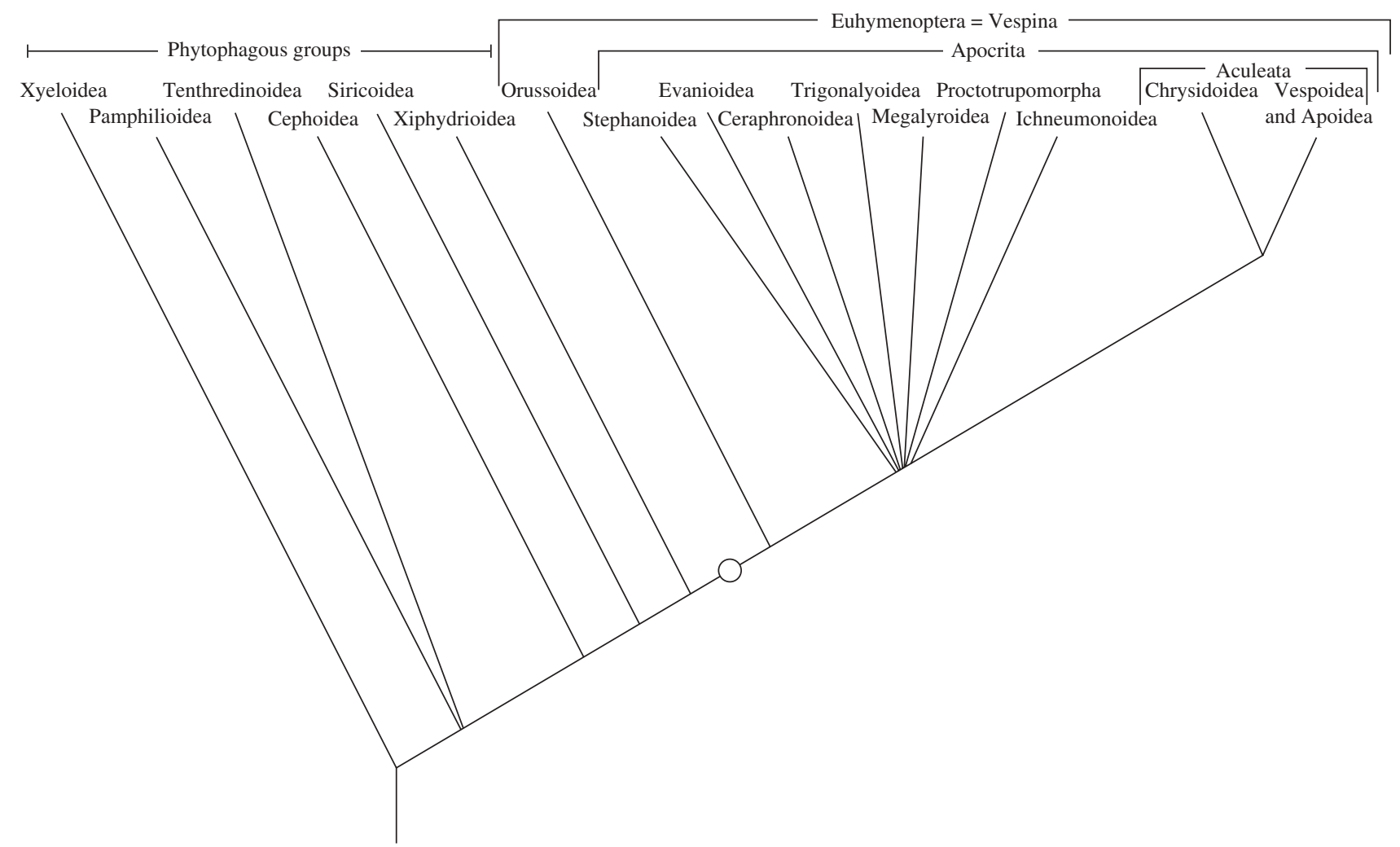

Figure 2. Cautious estimate of the phylogeny of Hymenoptera based on $[41,56,120,121]$ and recent molecular analyses by the HymAToL project (not yet published). Only relationships that are supported independently by morphological and molecular analyses are shown. The present study examined brains of species representing all groups indicated in the tree with the exception of the phytophagous Pamphilioidea. Proctotrupomorpha includes Chalcidoidea, Proctotrupoidea, Cynipoidea, Platygastroidea, Diaprioidea and Mymarommatoidea. Circle indicates the appearance of large, elaborate mushroom bodies at the base of the Euhymenoptera. Eusocial species are found only within the Vespoidea and Apoidea.

Rare species obtained as alcohol- or alcoholic Bouin'sfixed specimens were found to be unsuitable for paraffin histology and subsequent quantification owing to sectioning damage to the tissue. Better tissue condition for such specimens was obtained by post-fixing in 4 per cent paraformaldehyde followed by anti-DC0 immunostaining and brain region measurements as described above.

\section{(c) Fluorescent dextran fills of sensory inputs to the calyces}

Live insects were cold-anaesthetized, and brains removed rapidly in cold physiological saline. The tip of a pulled glass electrode was broken against a glass slide and then coated in a solution of 5 per cent Texas red- or fluoresceinconjugated $3000 \mathrm{MW}$ dextran (Molecular Probes, Inc. (Invitrogen), Eugene, OR, USA). The dextran-coated electrode was applied to the optic or antennal lobes by hand. Brains were then incubated in the dark at room temperature in physiological saline for $4 \mathrm{~h}$ on a rapidly rotating orbital shaker. Brains were fixed in 4 per cent paraformaldehyde, embedded in agarose, sectioned and viewed on the confocal microscope. Most of the brains processed in this way were also of suitable condition for brain region measurements, so confocal stacks of $10 \mu \mathrm{m}$ optical sections were captured and imported to IMAGEJ as described above.

\section{(d) Statistical analyses}

Volume measurements for the protocerebrum versus the mushroom bodies and the calyces versus the lobes were log-transformed, plotted and analysed using GRAPHPAD
PRISM 5.0c software (GRAPHPAD Software Inc., La Jolla, CA, USA). Linear regressions were fit for phytophagous species and Euhymenoptera, and slopes and intercepts compared between the two lines for the two groups using two-way analysis of covariance.

\section{RESULTS}

\section{(a) Mushroom body morphology in phytophagous} versus parasitoid Hymenoptera

Comparisons of a phytophagous species (Dolerus sp., Tenthredinidae, Tenthredinoidea) and a euhymenopteran parasitoid species (Ophion sp., Ichneumonidae, Ichneumonoidea) reveal dramatic differences in mushroom body size, calyx morphology and afferent input (figure 3). Both the Tenthredinidae and the Ichneumonidae are composed entirely of solitary species [43]. The mushroom bodies of tenthredinids possessed simple, ovoid calyces lacking subcompartments (figure $3 a$ ). Fluorescent dextran fills of the antennal lobes and optic lobes of tenthredinids labelled antennal lobe projection neurons innervating the entire calyx, and outputs from the optic neuropils that passed ventral to the calyces without providing collaterals (figure $3 b$ ). By contrast, the mushroom bodies of ichneumonids were large and elaborate (figure $3 c$ ), with calyces partitioned into subcompartments corresponding to the lip, collar and basal ring regions of aculeate species. Dextran-labelled projection neurons from the optic lobes innervated the calyx collar, but not the lip (figure $3 d$ ). 

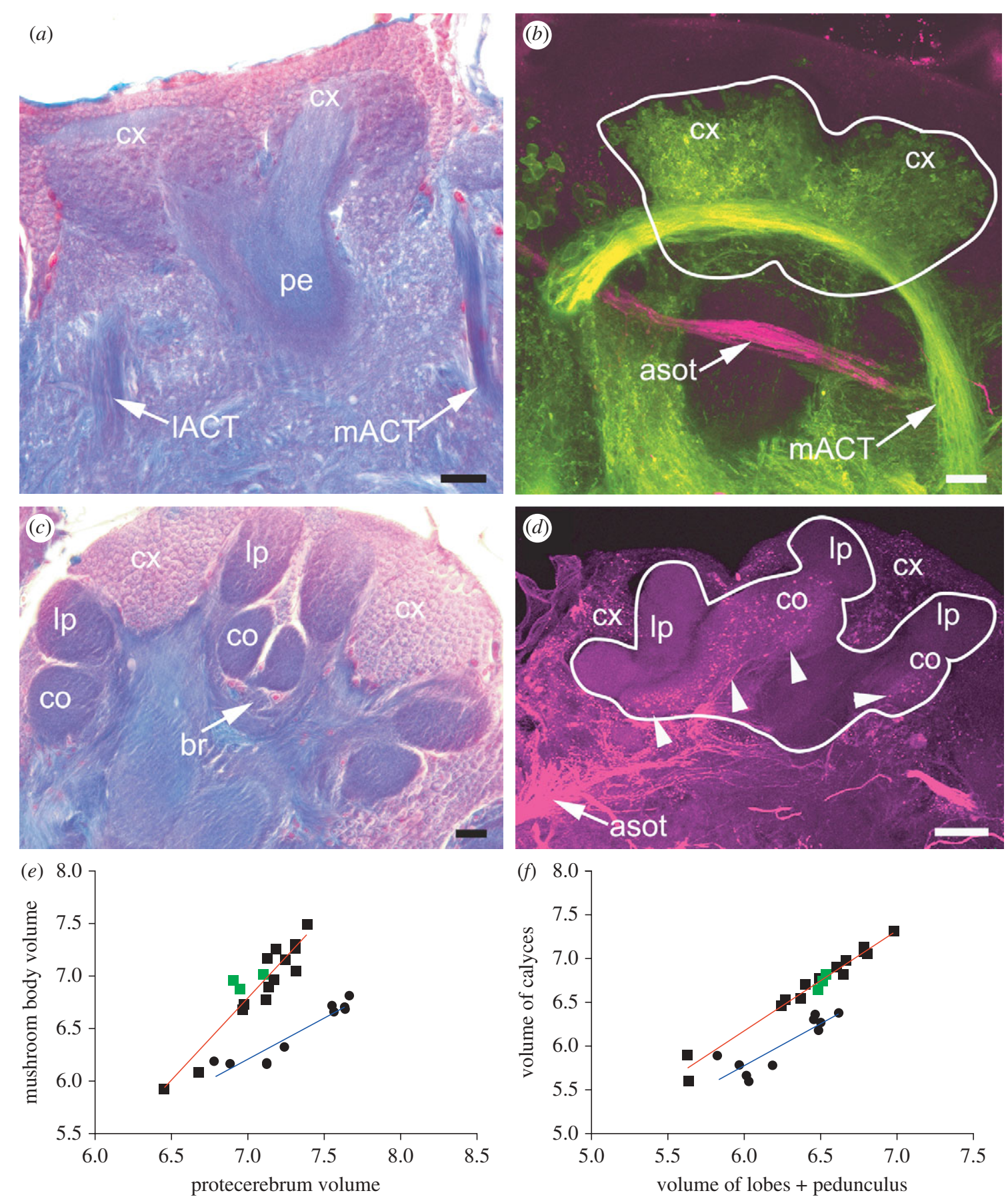

Figure 3. Comparisons of mushroom body morphology in phytophagous versus parasitoid Hymenoptera. (a) Mushroom bodies of the phytophagous Dolerus sp. (Tenthredinidae) showing simple, ovoid mushroom body calyces (cx) with no obvious compartmentalization into lip, collar or basal ring regions. (b) Dextran fills of the antennal lobes (green) reveal arborizations of olfactory projection neurons from the mACT throughout both calyces. Dextran fills of the optic lobes (magenta) label projection neuron axons in the anterior superior optic tract (asot), which passes beneath the mushroom bodies without providing collaterals to the calyces. (c) Mushroom bodies of the euhymenopteran parasitoid Ophion sp. (Ichneumonidae) have elaborate, deeply invaginated calyces divided into subcompartments like those observed in aculeate hymenopterans (lip (lp), collar (co) and basal ring (br), labelled in one calyx). (d) Dextran fills of the optic lobe of an ichneumonid reveal innervation of the calyx collar by optic lobe projection neurons (arrowheads). (e) Linear regression of log-transformed mushroom body volumes relative to the volume of the remaining protocerebrum in phytophagous (blue line) versus euhymenopteran (red line) species. Green points indicate measurements for the social aculeate Tetramorium caespitum (Formicidae, Vespoidea). $(f)$ Linear regression of log-transformed calyx volumes versus lobe volumes ( $n=10$ for phytophagous species, $n=17$ for parasitoid species). 1ACT, mACT; lateral and medial antennocerebral tracts. Scale bars $(a-c) 20 \mu \mathrm{m} ;(d) 50 \mu \mathrm{m}$.

For all species in which brain regions were measured (electronic supplementary material, table S1), the relationship between mushroom body volume and the volume of the remaining protocerebrum (not including the mushroom bodies or optic lobes) was linear for both the phytophagous species $\left(r^{2}=0.88\right)$ and euhymenopteran species $\left(r^{2}=0.86\right)$, but the slopes of the plotted lines were significantly different $(F=15.07, p=0.0008$; figure $3 e$ ). This suggests that the allometric relationship between the mushroom bodies and the protocerebrum 

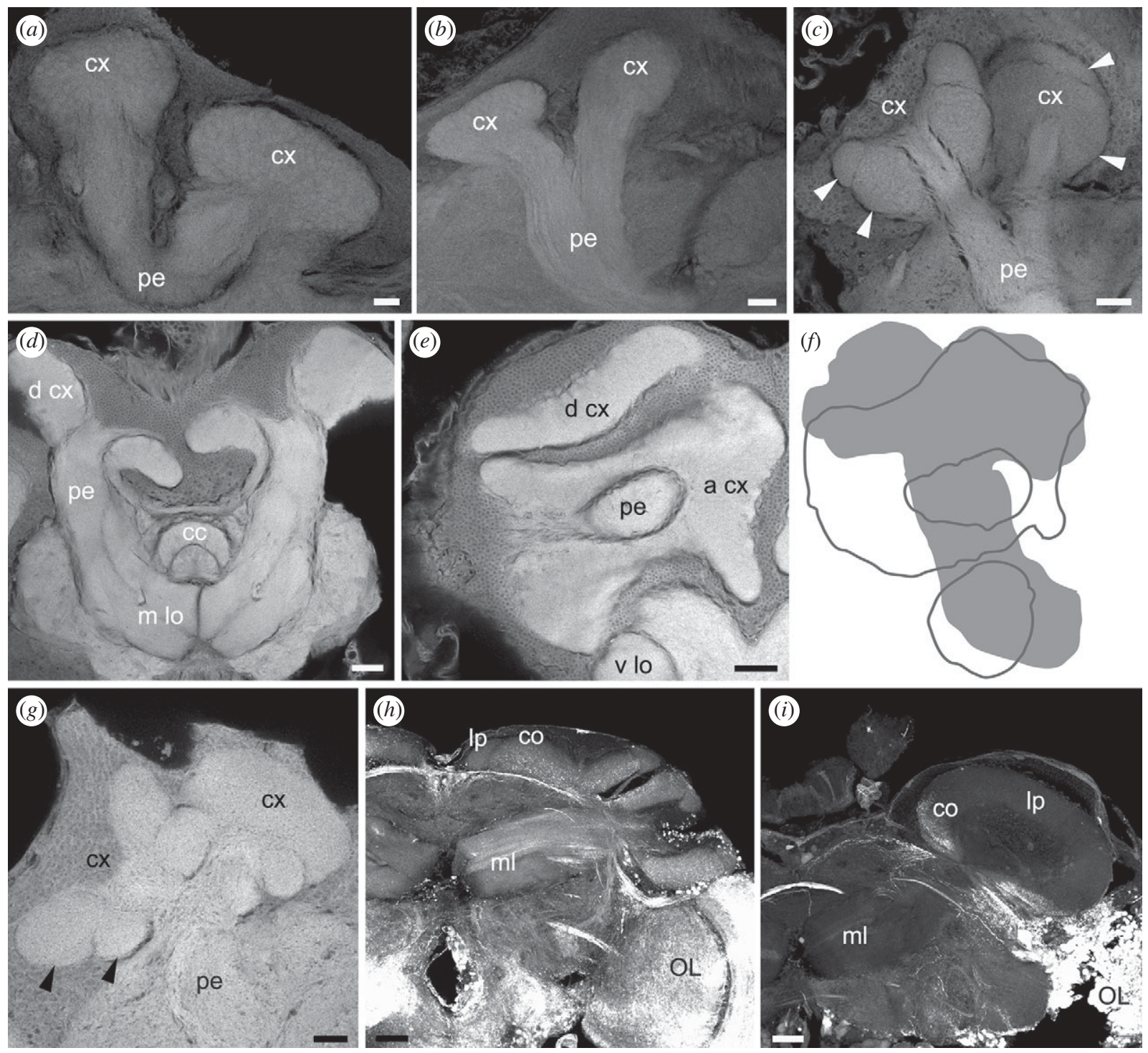

Figure 4. Mushroom body morphology in phytophagous and parasitoid Hymenoptera. Simple ovoid calyces (cx) without subcompartments were observed in the phytophagous (a) Tremex columba (Siricidae) and (b) Xiphydria maculata (Xiphydriidae). (c) The calyces of stem-boring sawflies such as Cephus spinipes (Cephidae) appeared to possess small subcompartments, although they were not otherwise elaborated like those of euhymenopterans $(d-i)$. $(d, e)$ The elaborate calyces of Orussus abietinus (Orussidae) were greatly enlarged, with one calyx oriented dorsally (d cx) and one anteriorly (a cx). $(f)$ Outline of the Orussus mushroom bodies illustrating the great size of the calyces. ( $g$ ) Subcompartments (arrowheads) in the elaborate calyces of the basal parasitoid Stephanus serrator (Stephanidae) are structurally similar to the lip and collar of the higher Euhymenoptera, suggesting that they are similarly subdivided by olfactory and visual inputs. $(h)$ Optic lobe dextran fills reveal visual input to collar (co) subcompartments of the elaborate calyces of the parasitoid Gasteruption sp. (Gasteruptiidae, Evanoidea). Unlabelled dorsal compartments probably correspond to the lip (lp). (i) The mushroom bodies of Leucospis sp. (Leucospidae, Chalcidoidea) possess a single flask-shaped calyx that receives dextran-labelled optic lobe projection neurons to a small ventral collar (co). Again, the dorsal unfilled compartment probably represents an olfactory input-receiving lip. Medial lobe (m lo); optic lobe (OL); pedunculus (pe); vertical lobe (v lo). Scale bars $(a-c, g) 20 \mu \mathrm{m} ;(d, e, h, i) 50 \mu \mathrm{m}$.

is different for the two groups of insects, such that mushroom body volume increases more with protocerebral volume in euhymenopterans. As a result, with the exception of the species with the smallest protocerebra (Megaspilus sp., and Stephanus serrator; indicative of small brain and thus body size; [33]), the mushroom bodies are larger relative to the protocerebrum in euhymenopterans. Despite their relatively small size, however, the mushroom bodies of both Megaspilus and Stephanus possessed invaginated and subcompartmentalized calyces typical of elaborate mushroom bodies (figure $4 g$ ). The relationship between calyx volume versus lobes + pedunculus volume was also linear in both phytophagous species $\left(r^{2}=0.76\right)$ and euhymenopteran species $\left(r^{2}=0.97\right)$, but the slopes were not significantly different $(F=1.58, p=0.22$; figure $3 f)$. Instead, the $y$-intercepts for these measurements were significantly different $(F=93.83, p<0.0001)$. This suggests a grade shift in the relationship between calyx volume and lobes + pedunculus volume [51,52], in which for a given volume of lobes + pedunculus, euhymenopterans have a significantly larger calyx, reflective of the expanded cup-shaped calyx morphology in these species.

For both comparisons (mushroom body versus protocerebral volume and calyx versus lobes + pedunculus volume), three points representing measurements made 
for the social aculeate Tetramorium caespitum (Formicidae, Vespoidea) fell near the regression line calculated for all Euhymenoptera (green points in figure $3 e, f$ ). Removing these points and recalculating the regressions did not significantly change the slope or the intercept of the line for either comparison $(r=0.92$ for mushroom bodies versus protocerebrum without Tetramorium data, $F=0.19, p=0.67$ for comparison of slopes; $F=0.55$, $p=0.46$ for comparison of intercepts; $r=0.97$ for calyx versus lobes + pedunculus without Tetramorium data, $F=0.0007, p=1.0$ for comparison of slopes; $F=0.04$, $p=0.84$ for comparison of intercepts).

\section{(b) Mushroom body morphology in phytophagous Hymenoptera}

To explore the transition from small, simple mushroom bodies to large, elaborate mushroom bodies in more detail, we first examined species from among the basal phytophagous lineages (electronic supplementary material, table S1). Macroxyela ferruginea, of the basal-most superfamily Xyeloidea [41], possessed mushroom bodies with simple, ovoid calyces lacking lip- or collar-like subcompartments (data not shown). Mushroom bodies of species representing the more derived families of the phytophagous Hymenoptera [38], Tremex columba (Siricoidea, figure $4 a$ ) and Xiphydria maculata (Xiphydrioidea, figure $4 b$ ) were of similar morphology to those of Macroxyela. Species of the phytophagous Cephoidea, Cephus spinipes and Calameuta filiformis, had subcompartments in the calyces (figure $4 c$ ), although the mushroom bodies were otherwise similar in morphology to those of the other phytophagous species (not elaborate; they fell within the linear fits for the other phytophagous species for mushroom body volume versus protocerebral volume and calyx volume versus lobes + pedunculus volume, figure $3 e, f)$. We were unable to identify the sources of afferent input to the cephid mushroom bodies from the tissue available for this study.

\section{(c) Mushroom body morphology in parasitoid Euhymenoptera}

Preparations of selected species spanning the parasitoid Euhymenoptera revealed the point of transition to large, elaborate mushroom bodies at the base of this clade. Wasps of the basal euhymenopteran superfamilies Orussoidea and Stephanoidea are ectoparasitoids of wood-boring insect larvae [38,39]. Mushroom bodies of the orussids Orussus abietinus (figure $4 d-f$ ) and Orussus occidentalis (data not shown) were dramatically expanded in size, with elaborate calyces that filled the dorsal and anterior brain (figure $4 d-f$ ). Although we could not determine with certainty whether there were subcompartments in the calyces of Orussus, they were distinctly larger when compared with those of the phytophagous hymenopterans, including the cephids. The mushroom bodies of Stephanus serrator (figure $4 g$ ) were also distinct from those of the phytophagous species, with elaborate calyces that were partitioned into subcompartments reminiscent of lip and collar regions. This suggests that the Stephanus calyces receive input from the optic lobes, although we were unable to confirm this in our alcohol-preserved specimens.
All of the remaining euhymenopteran species surveyed in this study were united with the social aculeates by possessing large, elaborate mushroom bodies with distinctly subcompartmentalized calyces (lip and collar; basal ring subcompartments were clearly identifiable only in the ichneumonids and aculeates). When fresh tissue was available, dextran fills to the optic lobes confirmed that the collar-like subcompartments of the calyces were innervated by optic lobe projection neurons.

Optic lobe dextran fills of the parasitoid Gasteruption sp. (Gasteruptiidae, Evaniodea) revealed large, elaborate mushroom bodies with clearly subcompartmentalized calyces that received input to the collar from optic lobe projection neurons (figure $4 h$ ). Smaller subcompartments dorsal to the collar were not innervated by optic lobe neurons, and are likely to correspond to the lip regions of aculeate Hymenoptera. The brains of three other apocritan parasitoids, Orthogonalys pulchella (Trigonalidae, Trigonalioidea), Megalyra sp. (Megalyridae, Megalyroidea) and Megaspilus sp. (Megaspilidae, Ceraphronoidea) possessed similar large and elaborate mushroom body morphologies (data not shown).

Species of the superfamily Chalcidoidea (Proctotrupomorpha) display diverse life histories and are among the smallest known insects $[53,54]$, although the family Leucospidae contains species that are of relatively larger size (10-15 mm). Leucospis sp. mushroom bodies were large and elaborate, but possessed only a single flask-shaped calyx (figure $4 i$ ). Dextran fills to the optic lobes revealed innervation of a small, layered collar subcompartment in the ventral calyx, with the uninnervated majority of the calyx neuropil presumably corresponding to the lip. A similar mushroom body morphology was observed in Ropronia sp. (Roproniidae, data not shown). It is possible that the loss of a calyx in both Ropronia and Leucospis reflect the effects of miniaturization in the Chalcidoidea, which may result in the reduction and loss of morphological elements [55]. The single calyx may also be a synapomorphy for a clade containing both the Roproniidae and Leucospidae within the monophyletic Proctotrupomorpha [43].

\section{(d) Mushroom body morphology in a solitary aculeate}

The Chrysidoidea are solitary aculeate wasps considered to be the sister group to the remaining two aculeate superfamilies Vespoidea and Apoidea [56]. Many chrysidids are cleptoparasitic, laying their eggs within the nests or burrows of other aculeate species. Chrysidid mushroom bodies were large and elaborate, with extensively convoluted calyces clearly subdivided into lip, collar and basal ring regions (figure $5 a$ ). Optic and antennal lobe dextran fills revealed that their inputs to the calyces were inverted with respect to what is typically observed (compare figure 1 with figure $5 b$ ): optic lobe input filled a massively expanded dorsal calyx compartment (magenta), while antennal lobe input targeted a far smaller ventral compartment (green). Visual projection neurons from the optic lobes also provided collaterals to the basal ring neuropil.

\section{DISCUSSION}

Eusociality is thought to have evolved at least four times independently in the aculeate Hymenoptera [43,44]. 

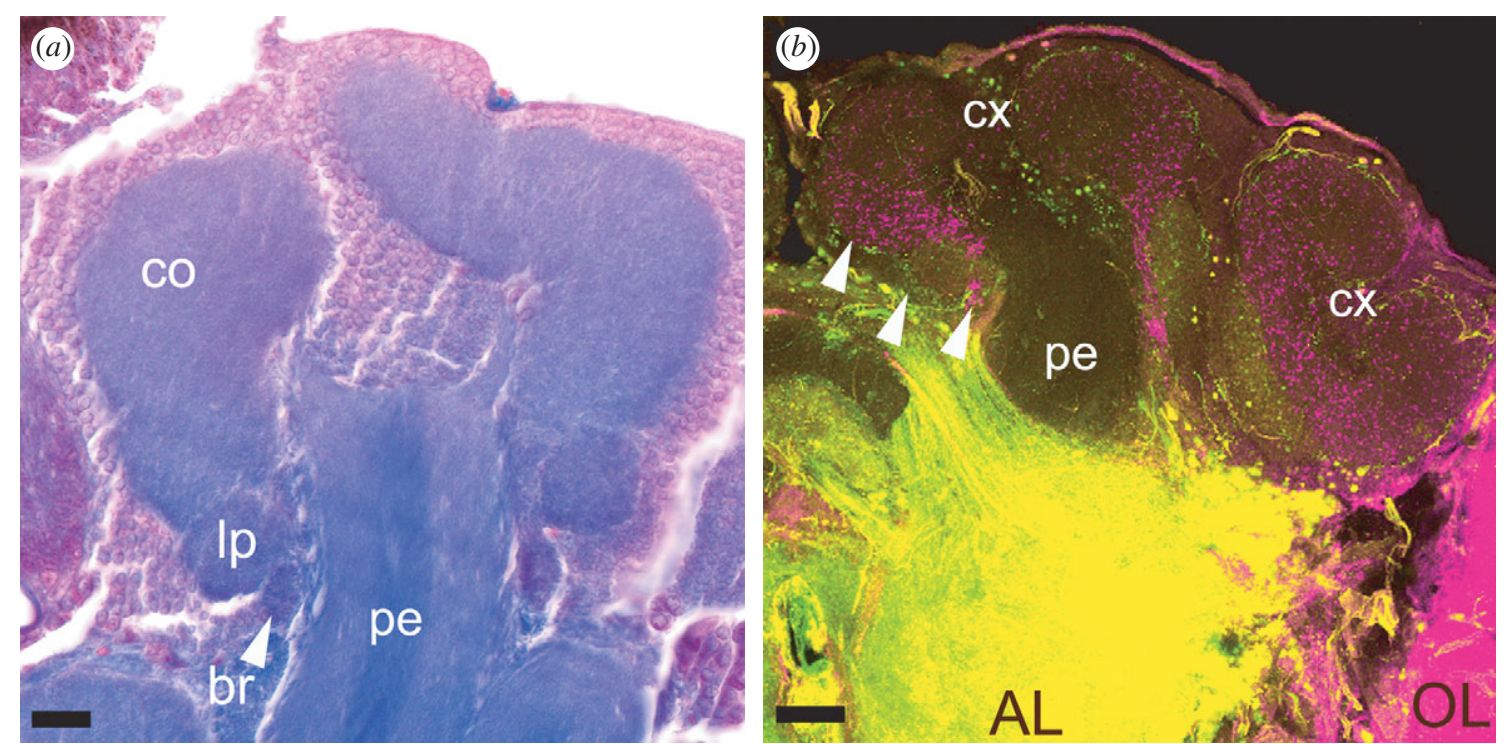

Figure 5. Mushroom body calyces of a solitary aculeate wasp (Chrysididae, Chrysidoidea). (a) Chrysidids have elaborate and deeply invaginated calyces (one visible here) with a clear lip, collar and basal ring (arrow). (b) Dextran fills of the antennal lobes (AL, green) and optic lobes (OL, magenta) show segregation of inputs into the calyx lip, collar and basal ring (arrows). The position of the collar and lip are inverted relative to what is observed in aculeates so that the greatly enlarged collar lies on top of the much smaller lip. Scale bars (a) $20 \mu \mathrm{m}$; (b) $50 \mu \mathrm{m}$.

All aculeates investigated to date, ranging from solitary to presocial to eusocial, possess large, elaborate mushroom bodies with lip, collar and basal ring subcompartments in the calyx; in species in which calyx inputs have been traced, the collar receives visual input from the optic lobes (the only exception being secondarily blind species of ants in which both the optic lobes and calyx collar have been lost) (electronic supplementary material, table S1) (present account; [31,50,57-60]). In facultatively social and eusocial aculeates, intraspecific differences in mushroom body size have been correlated with social hierarchy [61-64] and foraging and other types of behavioural experience $[50,65,66]$; these differences may also be seen at the cellular level in terms of Kenyon cell dendrite morphology in the calyx [67-71]. Similarly, in a facultatively social species outside of the Hymenoptera, the gregarious locust Schistocerca gregaria; gregarious phase individuals have larger mushroom body calyces than do solitarious individuals [51]. However, cross-species comparisons of solitary and social species of aculeate Hymenoptera have thus far revealed only relatively minor modifications of calyx subcompartments associated with social organization [72]. Taken together, it is clear that the evolution of sociality within the Aculeata did not drive the acquisition of elaborate mushroom bodies; it is more parsimonious to assume that the common ancestor of the aculeates already possessed elaborate mushroom bodies prior to the subsequent evolution of sociality.

Jawlowski [73] noted that ichneumonid parasitoid wasps, which are evolutionarily basal to the Aculeata, have large and elaborate mushroom bodies, although species belonging to the basal phytophagous lineages do not [74]. These findings together with the present account provide substantial evidence that the evolution of sociality did not drive the initial expansion and elaboration of the mushroom bodies in the Hymenoptera. Rather, mushroom body elaboration, marked by an increase in size and the expansion and subcompartmentalization of the calyces, occurred prior to the evolution of the Aculeata and the social groups within. Specifically, our results suggest that this event occurred at the base of the Euhymenoptera, concurrent with the acquisition of a parasitoid behavioural ecology (figure 2). The fossil record supports an early Jurassic origin for the first euhymenopteran parasitoids, while the first social aculeates are found in the early Cretaceous [43]. If parasitoidism evolved concurrently with elaborate mushroom bodies as the evidence presented here suggests, then this mushroom body morphology predated the advent of sociality by approximately $90 \mathrm{Myr}$.

What selective pressures might underlie the acquisition of elaborate mushroom bodies in parasitoid wasps? In both vertebrates and invertebrates, the capacity for flexible behaviours, such as those associated with food acquisition, is correlated with overall brain expansion $[21,27,47,49,75-77]$. In addition, behavioural ecologies that rely heavily on particular behaviours drive size increases in the necessary brain regions; for example, food-caching birds that employ spatial learning to remember the locations of hidden food items have larger hippocampuses [78], while pelagic sharks that pursue agile prey have larger cerebellums [79]. In insects, the acquisition of a generalist feeding ecology in scarab beetles is associated with an elaborate mushroom body morphology much like that observed in the Euhymenoptera [49], including expansion and subcompartmentalization of the calyces with the acquisition of optic lobe inputs [47]. Why might feeding generalists require larger mushroom bodies with direct visual inputs? Generalists not only need to perceive and process a wider variety of sensory cues to detect palatable food sources, but they may also need to learn and remember characteristics of food sources and their locations. As sensory integration, learning and memory centres, the mushroom bodies would play a role in these functions, and the increased size of elaborate mushroom bodies 
might provide additional circuitry for associating and remembering multiple sensory cues in time and space.

Many adult parasitoid wasps may be considered feeding generalists, visiting flowers to collect pollen and nectar, or collecting honeydew from homopteran insects [80]. However, the adults of most phytophagous hymenopterans have a similar feeding ecology [81], so this cannot explain the abrupt enlargement and elaboration of the mushroom bodies at the base of the Euhymenoptera. Our results imply that some novel aspect of the concurrently acquired parasitoid behavioural ecology required enhanced processing by morphologically elaborate mushroom bodies relative to what is employed by basal, non-parasitoid species. One possibility is increased demand for learning and memory capabilities employed during host location; parasitoids are adept at learning both visual and olfactory cues in this context [82-87]. In particular, spatial learning plays an important role in host location in some species. For example, the parasitoid Hyposoter horticola (Ichneumonidae) employs spatial learning to monitor previously identified hosts over a span of several days [86,87]. Similarly, Argochrysis armilla (Chrysididae; [88]) and Dasymutilla coccineohirta (Mutillidae, Vespoidea; [89]), both kleptoparasitic solitary aculeates, employ spatial learning to monitor the burrows of hosts. Species in all three families possess large, elaborate mushroom bodies (present account and [90]). Although host-finding behaviours occur only in females, males also possess elaborate mushroom bodies, as observed for many of the species of parasitoids surveyed in the present account (electronic supplementary material, table S1). In social aculeates as well, both sexes possess elaborate mushroom bodies although those of males are smaller in size [91]. This may be because mushroom body development does not differ dramatically between the sexes [92], so males may possess elaborate mushroom bodies even though their behavioural repertoire is simpler than that of females. In some parasitoid species, however, males may employ associative learning to assist in locating females [93], while males of social aculeates such as the honeybee may take repeated mating flights that require them to learn the location of the nest [94]; such behaviours may also be facilitated by elaborate mushroom bodies.

Laboratory studies in the cockroach Periplaneta americana, an insect which also possesses large, elaborate mushroom bodies that receive visual input [95], have shown that these brain centres are necessary for spatial learning $[4,5]$. By contrast, spatial learning in the fruitfly Drosophila melanogaster is supported by neurons in the central complex rather than the mushroom bodies [96-98], and the mushroom bodies in this species are small and do not receive visual input to the calyces [99]. Spatial learning in Drosophila also appears to be somewhat limited, as laboratory assays have demonstrated memories only for near-field visual cues that decay within minutes to hours $[98,100,101]$. It is possible that Drosophila does not rely extensively on spatial learning for locating food sources, mates or oviposition sites (all of which occur on fallen and rotting fruits which are likely to be clustered together in space [102]). However, for insects that must navigate among multiple distant sites for feeding and reproduction, learning the locations of these sites for repeat visits may be of importance. In such species, the processing demands of spatial learning may have promoted the evolution of larger mushroom bodies with novel circuits for processing visual information and forming associative and spatial memories. We may therefore predict that insects outside of the Hymenoptera, with different behavioural ecologies, may be expected to possess elaborate mushroom bodies if they rely heavily on associative and particularly spatial learning. For example, many lineages of flies (Diptera) are parasitoids; species in one group, the Bombyliidae, have larger mushroom bodies relative to those of nonparasitoid flies [103]. Species of Heliconius butterflies (Lepidoptera) that trapline foraging sites (repeatedly visiting learned host plant locations in a specific order) and return to a specific roost location each night also have larger mushroom bodies than do species that do not share these spatial learning-reliant behaviours [104]; the butterfly Pieris rapae possesses elaborate mushroom bodies that receive visual input, and individuals with larger mushroom bodies perform better at associating visual cues with host plants [105]. Finally, predatory species such as dragonflies that patrol their habitat from a central perch location have large mushroom bodies that receive visual input $[106,107]$. Thus, the preponderance of evidence suggests that insects which rely heavily upon spatial learning have acquired this particular mushroom body morphology, although a mechanistic understanding of the role of elaborate mushroom bodies in spatial learning awaits further studies.

The demand for associative and spatial learning is still present in the behavioural ecologies of modern aculeates, albeit in other contexts. Spatial learning is a necessity for the many aculeate Hymenoptera that are central place foragers, both solitary and social, in which burrows or nests containing eggs or larvae are provisioned with food through repeated foraging trips. These insects excel at learning the locations of food sources and nest sites in relation to visual landmarks [108-115]. Thus, mushroom bodies that were adapted for spatial learning in the context of host location by parasitoids may have been preadapted for spatial learning in the context of foraging from a central nest site as is observed in the solitary aculeates. The place-centred foraging ecology, in turn, was fertile ground for group nest construction and sociality, giving rise to social ants, bees and wasps on multiple independent occasions [116]. A similar trajectory may perhaps also be observed in the Dictyoptera, in which cockroaches possess large, elaborate mushroom bodies and gave rise to the eusocial termites, which also have large and complex mushroom bodies [117]. As sociality emerged in the Hymenoptera, enlarged mushroom bodies with the capacity for processing complex visual features may have further facilitated social interactions, such as the ability to recognize individuals using visual cues [118,119]. Future studies making use of the extensive behavioural diversity in the Hymenoptera will probably continue to reveal relationships between learning and memory, social behaviour and the evolution of mushroom body structure and function.

We thank Dr Kevin Daly and three anonymous reviewers for editorial comments that greatly improved the quality of this manuscript. This research was funded partially by National Science Foundation award no. 929572 to S.M.F. 


\section{REFERENCES}

1 McGuire, S. E., Le, P. T. \& Davis, R. L. 2001 The role of Drosophila mushroom body signaling in olfactory memory. Science 293, 1330-1333. (doi:10.1126/ science.1062622)

2 Perez-Orive, J., Mazor, O., Turner, G. C., Cassenaer, S., Wilson, R. I. \& Laurent, G. 2002 Oscillations and sparsening of odor representation in the mushroom body. Science 297, 359-365. (doi:10.1126/science.1070502)

3 Blum, A. L., Li, W., Cressy, M. \& Dubnau, J. 2009 Short- and long-term memory in Drosophila require cAMP signaling in distinct cell types. Curr. Biol. 19, 1341-1350. (doi:10.1016/j.cub.2009.07.016)

4 Mizunami, M., Weibrecht, J. M. \& Strausfeld, N. J. 1993 A new role for the insect mushroom bodies: place memory and motor control. In Biological neural networks in invertebrate neuroethology and robotics (eds R. D. Beer, R. E. Ritzman \& T. McKenna), pp. 199-225. New York, NY: Academic Press.

5 Mizunami, M., Weibrecht, J. M. \& Strausfeld, N. J. 1998 Mushroom bodies of the cockroach: their participation in place memory. F. Comp. Neurol. 402, 520-537. (doi:10.1002/(SICI) 1096-9861(19981228) 402:4<520::AID-CNE6>3.0.CO;2-K)

6 Schildberger, K. 1984 Multimodal interneurons in the cricket brain: properties of identified extrinsic mushroom body cells. F. Comp. Physiol. 154, 71-79. (doi:10.1007/BF00605392)

7 Li, Y.-S. \& Strausfeld, N. J. 1999 Multimodal efferent and recurrent neurons in the medial lobes of cockroach mushroom bodies. F. Comp. Neurol. 409, 647-663. (doi:10.1002/(SICI)1096-9861(19990712)409:4<647:: AID-CNE9>3.0.CO;2-3)

8 Brembs, B. \& Wiener, J. 2006 Context and occasion setting in Drosophila visual learning. Learn. Mem. 13, 618-628. (doi:10.1101/lm.318606)

9 Peng, Y., Xi, W., Zhang, K. \& Guo, A. 2007 Experience improves feature extraction in Drosophila. F. Neurosci. 27, 5139-5145. (doi:10.1523/JNEUROSCI.0472-07.2007)

10 Xi, W., Peng, Y., Guo, J., Ye, Y., Zhang, K., Yu, F. \& Guo, A. 2008 Mushroom bodies modulate saliencebased fixation behavior in Drosophila. Eur. F. Neurosci. 27, 1441-1451. (doi:10.1111/j.1460-9568.2008.06114.x)

11 Brembs, B. 2009 Mushroom bodies regulate habit formation in Drosophila. Curr. Biol. 19, 1-5.

12 Van Swinderen, B. \& Brembs, B. 2010 Attention-like deficit and hyperactivity in a Drosophila memory mutant. F. Neurosci. 30, 1003-1014. (doi:10.1523/ JNEUROSCI.4516-09.2010)

13 Kenyon, F. C. 1896 The brain of the bee. A preliminary contribution to the morphology of the nervous system of the Arthropoda. F. Comp. Neurol. 6, 133-210. (doi:10. 1002/cne.910060302)

14 Strausfeld, N. J. 1976 Atlas of an insect brain. Berlin, Germany: Springer.

15 Strausfeld, N. J., Hansen, L., Li, Y.-S., Gomez, R. S. \& Ito, K. 1998 Evolution, discovery and interpretations of arthropod mushroom bodies. Learn. Mem. 5, 11-37.

16 Farris, S. M. 2005 Evolution of insect mushroom bodies: old clues, new insights. Arthropod Struct. Dev. 34, 211-234. (doi:10.1016/j.asd.2005.01.008)

17 Dujardin, F. 1850 Mémoire sur le système nerveux des insectes. Ann. Sci. Natl Zool. 14, 195-206.

18 von Alten, H. 1910 Zur Phylogenie des Hymenopterengehirns. Fenaische Zeitschrift für Naturwissenschaft 46, 511-590.

19 Howse, P. E. 1975 Brain structure and behavior in insects. Annu. Rev. Entomol. 20, 359-379. (doi:10. 1146/annurev.en.20.010175.002043)
20 Gronenberg, W. \& Riveros, A. J. 2009 Social brains and behavior: past and present. In Organization of insect societies (eds J. Gadau \& J. Fewell), pp. 377-401. Boston, MA: Harvard University Press.

21 Barton, R. A. 1996 Neocortex size and behavioural ecology in primates. Proc. R. Soc. Lond. B 263, 173-177. (doi:10.1098/rspb.1996.0028)

22 Burish, M. J., Kueh, H. Y. \& Wang, H. 2004 Brain architecture and social complexity in modern and ancient birds. Brain Behav. Evol. 63, 107-124. (doi:10.1159/000075674)

23 Byrne, R. W. \& Bates, L. A. 2007 Sociality, evolution and cognition. Curr. Biol. 17, R714-R723. (doi:10. 1016/j.cub.2007.05.069)

24 Dunbar, R. I. M. \& Shultz, S. 2007 Evolution in the social brain. Science 317, 1344-1347. (doi:10.1126/ science.1145463)

25 Pérez-Barbería, F. J., Shultz, S. \& Dunbar, R. I. M. 2007 Evidence for coevolution of sociality and relative brain size in three orders of mammals. Evolution 61, 2811-2821. (doi:10.1111/j.1558-5646.2007.00229.x)

26 Schulz, S. \& Dunbar, R. I. M. 2006 Both social and ecological factors predict ungulate brain size. Proc. $R$. Soc. B 273, 207-215. (doi:10.1098/rspb.2005.3283)

27 Schulz, S. \& Dunbar, R. I. M. 2007 The evolution of the social brain: anthropoid primates contrast with other vertebrates. Proc. R. Soc. B 274, 2429-2436. (doi:10.1098/rspb.2007.0693)

28 Finarelli, J. A. \& Flynn, J. J. 2009 Brain-size evolution and sociality in Carnivora. Proc. Natl Acad. Sci. USA 106, 9345-9349. (doi:10.1073/pnas.0901780106)

29 MacLean, E. L., Barrickman, N. L., Johnson, E. M. \& Wall, C. E. 2009 Sociality, ecology, and relative brain size in lemurs. F. Hum. Evol. 56, 471-478. (doi:10. 1016/j.jhevol.2008.12.005)

30 Mobbs, P. G. 1982 The brain of the honeybee Apis mellifera $\mathrm{L}$. The connections and spatial organization of the mushroom bodies. Phil. Trans. R. Soc. Lond. B 298, 309-354. (doi:10.1098/rstb.1982.0086)

31 Gronenberg, W. 2001 Subdivisions of hymenopteran mushroom body calyces by their afferent supply. f. Comp. Neurol. 436, 474-489.

32 Strausfeld, N. J. 2002 Organization of the honey bee mushroom body: representation of the calyx within the vertical and gamma lobes. F. Comp. Neurol. 450, 4-33. (doi:10.1002/cne.10285)

33 Mares, S., Ash, L. \& Gronenberg, W. 2005 Brain allometry in bumblebee and honey bee workers. Brain Behav. Evol. 66, 50-61. (doi:10.1159/000085047)

34 Schröter, U. \& Menzel, R. 2003 A new ascending sensory tract to the calyces of the honeybee mushroom body, the subesophageal-calycal tract. F. Comp. Neurol. 465, 168-178. (doi:10.1002/cne.10843)

35 Farris, S. M. 2008 Tritocerebral tract input to the insect mushroom bodies. Arthropod Struct. Dev. 37, 492-503. (doi:10.1016/j.asd.2008.05.005)

36 Paulk, A. C. \& Gronenberg, W. 2008 Higher order visual input to the mushroom bodies in the bee, Bombus impatiens. Arthropod Struct. Dev. 37, 443-458. (doi:10.1016/j.asd.2008.03.002)

37 Ehmer, B. \& Gronenberg, W. 2002 Segregation of visual input to the mushroom bodies in the honeybee (Apis mellifera). F. Comp. Neurol. 451, 362-373. (doi:10. 1002/cne.10355)

38 Whitfield, J. B. 2003 Phylogenetic insights into the evolution of parasitism in Hymenoptera. Adv. Parasitol. 54, 69-100. (doi:10.1016/S0065-308X(03)54002-7)

39 Whitfield, J. B. 1998 Phylogeny and evolution of hostparasitoid interactions in Hymenoptera. Annu. Rev. 
Entomol. 43, 129-151. (doi:10.1146/annurev.ento. 43.1.129)

40 Vilhelmsen, L., Isidoro, N., Romani, R., Basibuyuk, H. H. \& Quicke, D. L. J. 2001 Host location and oviposition in a basal group of parasitic wasps: the subgenual organ, ovipositor apparatus and associated structures in the Orussidae (Hymenoptera, Insecta). Zoomorphology 121, 63-84. (doi:10.1007/s004350100046)

41 Schulmeister, S. 2003 Simultaneous analysis of basal Hymenoptera (Insecta): introducing robust-choice sensitivity analysis. Biol. F. Linn. Soc. 79, 245-275. (doi:10.1046/j.1095-8312.2003.00233.x)

42 Schulmeister, S. 2003 Review of morphological evidence on the phylogeny of basal Hymenoptera (Insecta), with a discussion of the ordering of characters. Biol. F. Linn. Soc. 79, 209-243. (doi:10. 1046/j.1095-8312.2003.00232.x)

43 Grimaldi, D. A. \& Engel, M. S. 2005 Evolution of the insects. New York, NY: Cambridge University Press.

44 Hunt, J. H. 1999 Trait mapping and salience in the evolution of eusocial vespid wasps. Evolution 53, 225-237. (doi:10.2307/2640935)

45 O'Shea, M. \& Adams, M. 1981 Pentapeptide (proctolin) associated with an identified neuron. Science 213, 567-569. (doi:10.1126/science.6113690)

46 Kiernan, J. 1990 Histological and histochemical methods: theory and practice, 2nd edn. Oxford, UK: Pergamon Press.

47 Farris, S. M. 2008 Structural, functional and developmental convergence of the insect mushroom bodies with higher brain centers of vertebrates. Brain Behav. Evol. 72, 1-15. (doi:10.1159/000139457)

48 Skoulakis, E. M. C., Kalderon, D. \& Davis, R. L. 1993 Preferential expression in mushroom bodies of the catalytic subunit of protein kinase $\mathrm{A}$ and its role in learning and memory. Neuron 11, 197-208. (doi:10.1016/08966273(93)90178-T)

49 Farris, S. M. \& Roberts, N. S. 2005 Coevolution of generalist feeding ecologies and gyrencephalic mushroom bodies in insects. Proc. Natl Acad. Sci. USA 102, 17 394-17 399. (doi:10.1073/pnas.0508430102)

50 Withers, G. S., Day, N. F., Talbot, E. F., Dobson, H. E. M. \& Wallace, C. S. 2008 Experience-dependent plasticity in the mushroom bodies of the solitary bee Osmia lignaria (Megachilidae). Dev. Neurobiol. 68, 73-82. (doi:10.1002/dneu.20574)

51 Ott, S. R. \& Rogers, S. M. 2010 Gregarious phase locusts have substantially larger brains with altered proportions compared with the solitarious phase. Proc. $R$. Sci. B 277, 3087-3096. (doi:10.1098/rspb.2010.0694)

52 Striedter, G. F. 2005 Principles of brain evolution. Sunderland, MA: Sinauer Associates Inc.

53 Gibson, G. A. P., Herarty, J. M. \& Woolley, J. B. 1999 Phylogenetics and classification of Chalcidoidea and Mymarommatoidea: a review of current concepts (Hymenoptera, Apocrita). Zool. Scripta 28, 87-124. (doi:10.1046/j.1463-6409.1999.00016.x)

54 Triplehorn, C. A. \& Johnson, N. F. 2005 Borror and DeLong's introduction to the study of insects, 7th edn. Belmont, CA: Thomson Brooks/Cole.

55 Yeh, J. 2002 The effect of miniaturized body size on skeletal morphology in frogs. Evolution 56, 628-641.

56 Brothers, D. J. \& Carpenter, J. M. 1993 Phylogeny of the Aculeata: Chrysidoidea and Vespoidea (Hymenoptera). f. Hymenoptera Res. 2, 227-304.

57 Jawlowski, H. 1959 The structure of corpora pedunculata in Aculeata (Hymenoptera). Folia Biol. 7, 61-70.

58 Gronenberg, W. \& Hölldobler, B. 1999 Morphologic representation of visual and antennal information in the ant brain. F. Comp. Neurol. 412, 229-240.
(doi:10.1002/(SICI) 1096-9861(19990920)412:2<229:: AID-CNE4>3.0.CO;2-E)

59 Ehmer, B. \& Hoy, R. R. 2000 Mushroom bodies of vespid wasps. F. Comp. Neurol. 416, 93-100. (doi:10.1002/(SICI)1096-9861(20000103)416:1<93:: AID-CNE7>3.0.CO;2-F)

60 Lòpez-Riquelme, G. O. \& Gronenberg, W. 2004 Multisensory convergence in the mushroom bodies of ants and bees. Acta. Biol. Hung. 55, 31-37.

61 Molina, Y. \& O’Donnell, S. 2007 Mushroom body volume is related to social aggression and ovary development in the paper wasp Polistes instabilis. Brain Behav. Evol. 70, 137-144. (doi:10.1159/000102975)

62 O’Donnell, S., Donlan, N. \& Jones, T. 2007 Developmental and dominance-associated differences in mushroom body structure in the paper wasp Misocyttarus mastigophorus. Dev. Neurobiol. 67, 39-46. (doi:10.1002/dneu.20324)

63 Molina, Y. \& O'Donnell, S. 2008 Age, sex, and dominance-related mushroom body plasticity in the paperwasp Mischocyttarus mastigophorus. Dev. Neurobiol. 68, 950-959. (doi:10.1002/dneu.20633)

64 Smith, A. R., Seid, M. A., Jiménez, L. C. \& Wcislo, W. T. 2010 Socially induced brain development in a facultatively eusocial sweat bee Megalopta genalis (Halictidae). Proc. R. Soc. B 277, 2157-2163. (doi:10. 1098/rspb.2010.0269)

65 Withers, G. S., Fahrbach, S. E. \& Robinson, G. E. 1993 Selective neuroanatomical plasticity and division of labour in the honeybee. Nature 364, 238-240. (doi:10. 1038/364238a0)

66 Durst, C., Eichmuller, S. \& Menzel, R. 1994 Development and experience lead to increased volume of subcompartments of the honeybee mushroom body. Behav. Neural Biol. 62, 259-263. (doi:10.1016/S01631047(05)80025-1)

67 Groh, C. \& Rössler, W. 2008 Caste-specific postembryonic development of primary and secondary olfactory centers in the female honeybee brain. Arthropod Struct. Dev. 37, 459-468. (doi:10.1016/j.asd.2008.04.001)

68 Krofczik, S., Khojasteh, U., Hempel de Ibarra, N. \& Menzel, R. 2008 Adaptation of microglomerular complexes in the honeybee mushroom body lip to manipulations of behavioral maturation and sensory experience. Dev. Neurobiol. 68, 1007-1017. (doi:10. 1002/dneu.20640)

69 Seid, M. A. \& Wehner, R. 2009 Delayed axonal pruning in the ant brain: a study of developmental trajectories. Dev. Neurobiol. 69, 350-364. (doi:10.1002/dneu.20709)

70 Hourcade, B., Muenz, T. S., Sandoz, J.-C., Rössler, W. \& Devaud, M. 2010 Long-term synaptic reorganization in the mushroom bodies: a memory trace in the insect brain? F. Neurosci. 30, 6461-6465. (doi:10.1523/ JNEUROSCI.0841-10.2010)

71 Stieb, S. M., Muenz, T. S., Wehner, R. \& Rössler, W. 2010 Visual experience and age affect synaptic organization in the mushroom bodies of the desert ant Cataglyphis fortis. Dev. Neurobiol. 70, 408-423. (doi:10.1002/dneu.20785)

72 Molina, Y., Harris, R. M. \& O’Donnell, S. 2009 Brain organization mirrors caste differences, colony founding and nest architecture in paper wasps (Hymenoptera: Vespidae). Proc. R. Soc. B 276, 3345-3351. (doi:10. 1098/rspb.2009.0817)

73 Jawlowski, H. 1959 On the brain structure of the Ichneumonidae. Bulletin de l'Academie Polonaise des Sciences Cl. II. Serie des Sciences Biologiques 8, 123-125.

74 Jawlowski, H. 1960 On the brain structure of the Symphyta (Hymenoptera). Bulletin de l'Academie Polonaise des Sciences. Serie des Sciences Biologiques 8, 265-268. 
75 Lefebvre, L., Reader, S. M. \& Sol, D. 2004 Brains, innovations and evolution in birds and primates. Brain Behav. Evol. 63, 233-246. (doi:10.1159/000076784)

76 Sol, D., Duncan, R. P., Blackburn, T. M., Cassey, P. \& Lefebvre, L. 2005 Big brains, enhanced cognition, and response of birds to novel environments. Proc. Natl Acad. Sci. USA 102, 5460-5465. (doi:10.1073/pnas. 0408145102)

77 Sol, D., Lefebvre, L. \& Rodriguez-Teijeiro, J. D. 2005 Brain size, innovative propensity and migratory behavior in temperate Palearctic birds. Proc. R. Soc. B 272, 1433-1441. (doi:10.1098/rspb.2005.3099)

78 Lucas, J. R., Brodin, A., de Kort, S. R. \& Clayton, N. S. 2004 Does hippocampal size correlate with the degree of caching specialization? Proc. R. Soc. Lond. B 271, 2423-2429. (doi:10.1098/rspb.2004.2912)

79 Yopak, K. E., Lisney, T. J., Collin, S. P. \& Montgomery, J. C. 2007 Variation in brain organization and cerebellar foliation in chondrichthyans: sharks and holocephalans. Brain Behav. Evol. 69, 280-300. (doi:10.1159/ 000100037)

80 Jervis, M. A., Kidd, N. A. C. \& Walton, M. 1992 A review of methods for determining dietary range in adult parasitoids. Entomophaga 37, 565-574. (doi:10. 1007/BF02372326)

81 Willemstein, S. C. 1987 An evolutionary basis for pollination ecology. Leiden, The Netherlands: E.J. Brill.

82 Papaj, D. R. \& Vet, L. E. M. 1990 Odor learning and foraging success in the parasitoid Leptopilina heterotoma. f. Chem. Ecol. 16, 3137-3150. (doi:10.1007/ BF00979616)

83 Sheehan, W., Wäckers, F. L. \& Lewis, W. J. 1993 Discrimination of previously searched, host-free sites by Microplitis croceipes (Hymenoptera: Braconidae). $\mathcal{F}$. Insect Behav. 6, 323-331. (doi:10.1007/BF01048113)

84 Turlings, T. C. J., Wäckers, R. L., Vet, L. E. M., Lewis, W. J. \& Tumlinson, J. H. 1993 Learning of hostfinding cues by hymenopterous parasitoids. In Insect learning: ecological and evolutionary perspectives (eds D. R. Papaj \& A. Lewis), pp. 51-78. New York, NY: Chapman \& Hall.

85 Steidle, J. L. M. 1998 Learning pays off: influence of experience on host finding and parasitism in Lariophagus distinguendus. Ecol. Entomol. 23, 451-456. (doi:10.1046/ j.1365-2311.1998.00144.x)

86 Van Nouhuys, S. \& Ehrnsten, J. 2004 Wasp behavior leads to uniform parasitism of a host available for only a few hours per year. Behav. Ecol. 15, 661-665. (doi:10.1093/beheco/arh059)

87 Van Nouhuys, S. \& Kaartinen, R. 2008 A parasitoid wasp uses landmarks while monitoring potential resources. Proc. $R$. Soc. $B$ 275, 377-385. (doi:10. 1098/rspb.2007.1446)

88 Rosenheim, J. A. 1987 Host location and exploitation by the cleptoparasitic wasp Argochrysis armilla: the role of learning (Hymenoptera: Chrysididae). Behav. Ecol. Sociobiol. 21, 401-406. (doi:10.1007/BF00299935)

89 VanderSal, N. D. 2008 Rapid spatial learning in a velvet ant (Dasymutilla coccineohirta). Anim. Cogn. 11, 563-567. (doi:10.1007/s10071-008-0145-4)

90 Strausfeld, N. J. 2001 Insect brain. In Brain, evolution and cognition (eds G. Roth \& M. F. Wulliman), pp. 367-400. New York, NY: John Wiley and Sons.

91 Ehmer, B. \& Gronenberg, W. 2004 Mushroom body volumes and visual interneurons in ants: comparison between sexes and castes. F. Comp. Neurol. 469, 198213. (doi:10.1002/cne.11014)

92 Roat, T. C. \& da Cruz Landim, C. 2008 Temporal and morphological differences in post-embryonic differentiation of the mushroom bodies in the brain of workers, queens, and drones of Apis mellifera (Hymenoptera, Apidae). Micron 39, 1171-1178. (doi:10.1016/j.micron.2008.05.004)

93 Godfray, H. C. J. 1994 Parasitoids: behavioral and evolutionary ecology. Princeton, NJ: Princeton University Press.

94 Fahrboch, S. E., Giray, T., Farris, S. M. \& Robinson, G. E. 1997 Expansion of the neuropil of the mushroom bodies in male honey bees is coincident with initiation of flight. Neurosci. Lett. 236, 135-138. (doi:10.1016/ S0304-3940(97)00772-6)

95 Li, Y.-S. \& Strausfeld, N. J. 1997 Morphology and sensory modality of mushroom body extrinsic neurons in the brain of the cockroach, Periplaneta americana. 7. Comp. Neurol. 387, 631-650. (doi:10.1002/ (SICI) 1096-9861(19971103)387:4<631::AID-CNE9> 3.0.CO;2-3)

96 Wolf, R., Wittig, T., Liu, L., Wustmann, G., Eyding, D. \& Heisenberg, M. 1998 Drosophila mushroom bodies are dispensable for visual, tactile, and motor learning. Learn. Mem. 5, 166-178.

97 Liu, G., Seiler, H., Wen, A., Zars, T., Ito, K., Wolf, R., Heisenberg, M. \& Liu, L. 2006 Distinct memory traces for two visual features in the Drosophila brain. Nature 439, 551-556. (doi:10.1038/nature04381)

98 Neuser, K., Triphan, T., Mronz, M., Poeck, B. \& Strauss, R. 2008 Analysis of a spatial orientation memory in Drosophila. Nature 453, 1244-1247. (doi:10.1038/nature07003)

99 Strausfeld, N. J., Sinakevitch, I. \& Vilinsky, I. 2003 The mushroom bodies of Drosophila melanogaster: an immunocytological and Golgi study of Kenyon cell organization in the calyces and lobes. Microsc. Res. Tech. 62, 151-169. (doi:10.1002/jemt.10368)

100 Putz, G. \& Heisenberg, M. 2002 Memories in Drosophila heat-box learning. Learn. Mem. 9, 349359. (doi:10.1101/1m.50402)

101 Zars, T. 2009 Spatial orientation in Drosophila. F. Neurogenet. 23, 104-110. (doi:10.1080/01677060802441364)

102 Markow, T. A. 1988 Reproductive behavior of Drosophila melanogaster and D. nigrospiracula in the field and in the laboratory. F. Comp. Psychol. 102, 169-173. (doi:10.1037/0735-7036.102.2.169)

103 Panov, A. A. 2009 General structure of the mushroom body calyx in Brachycera Orthorrapha flies (Diptera). Biol. Bull. 36, 267-276.

104 Sivinski, J. 1989 Mushroom body development in nymphalid butterflies: a correlate of learning? f. Insect. Behav. 2, 277-283. (doi:10.1007/BF01053299)

105 Snell-Rood, E. C., Papaj, D. R. \& Gronenberg, W. 2009 Brain size: a global or induced cost of learning? Brain. Behav. Evol. 72, 111-128.

106 Svidersky, V. L. \& Plotnikova, S. I. 2004 On structuralfunctional organization of dragonfly mushroom bodies and some general considerations about purpose of these formations. F. Evol. Biochem. Physiol. 40, 608-624. (doi:10.1007/s10893-005-0018-2)

107 Strausfeld, N. J., Sinakevitch, I., Brown, S. M. \& Farris, S. M. 2009 Ground plan of the insect mushroom body: functional and evolutionary implications. f. Comp. Neurol. 513, 265-291. (doi:10.1002/cne.21948)

108 Tinbergen, N. 1972 On the orientation of the digger wasp Philanthus trangulum Fabr. I. In The animal in its world, vol. 1 (ed. N. Tinbergen), pp. 103-127. Cambridge, MA: Harvard University Press.

109 Capaldi, E. A. \& Dyer, F. C. 1999 The role of orientation flights on homing performance in honeybees. f. Exp. Biol. 202, 1655-1666.

110 Zhang, S., Lehrer, M. \& Srinivasan, M. V. 1999 Honeybee memory: navigation by associative grouping 
and recall of visual stimuli. Neurobiol. Learn. Mem. 72, 180-201. (doi:10.1006/nlme.1998.3901)

111 Collett, T. S., Collett, M. \& Wehner, R. 2001 The guidance of desert ants by extended landmarks. f. Exp. Biol. 204, 1635-1639.

112 Fukushi, T. \& Wehner, R. 2004 Navigation in wood ants Formica japonica: context dependent use of landmarks. F. Exp. Biol. 207, 3431-3439. (doi:10.1242/ jeb.01159)

113 Warrant, E. J., Kelber, A., Gislén, A., Greiner, B., Ribi, W. \& Wcislo, W. T. 2004 Nocturnal vision and landmark orientation in a tropical halictid bee. Curr. Biol. 14, 1309-1318. (doi:10.1016/j.cub.2004.07.057)

114 Menzel, R. et al. 2005 Honey bees navigate according to a map-like spatial memory. Proc. Natl Acad. Sci. USA 102, 3040-3045. (doi:10.1073/pnas.0408550102)

115 Saleh, N. \& Chittka, L. 2007 Traplining in bumblebees (Bombus impatiens): a foraging strategy's ontogeny and the importance of spatial reference memory in shortrange foraging. Oecologia 151, 719-730. (doi:10.1007/ s00442-006-0607-9)
116 Wilson, E. O. \& Hölldobler, B. 2005 Eusociality: origins and consequences. Proc. Natl Acad. Sci. USA 102, 13 367-13 371. (doi:10.1073/pnas.0505858102)

117 Farris, S. M. \& Strausfeld, N. J. 2003 A unique mushroom body substructure common to both basal cockroaches and to termites. F. Comp. Neurol. 456, 305-320. (doi:10.1002/cne.10517)

118 Tibbetts, E. A. 2002 Visual signals of individual identity in the wasp Polistes fuscatus. Proc. R. Soc. Lond. B 269, 1423-1428. (doi:10.1098/rspb.2002.2031)

119 Sheehan, M. J. \& Tibbetts, E. A. 2008 Robust longterm social memories in a paper wasp. Curr. Biol. 18, $851-852$.

120 Dowton, M. \& Austin, A. D. 1994 Molecular phylogeny of the insect order Hymenoptera: apocritan relationships. Proc. Natl Acad. Sci. USA 91, 9911-9915. (doi:10.1073/pnas.91.21.9911)

121 Vilhelmsen, L. 2001 Phylogeny and classification of the extant basal lineages of the Hymenoptera. Zool. F. Linn. Soc. 131, 393-442. (doi:10.1111/j.1096-3642.2001. tb01320.x) 